\title{
First Line Anti-Tuberculosis Drugs Resistance Patterns of Mycobacterium tuberculosis Isolates from Newly Diagnosed Cases of Tuberculosis
}

\author{
Yogita Mistry*, Sangita Rajdev, Summaiya Mullan \\ Intermediate Reference laboratory for Tuberculosis, Surat, India \\ Email: dryogitamistry@gmail.com
}

How to cite this paper: Mistry, Y., Rajdev, S. and Mull, S. (2017) First Line Anti-Tuberculosis Drugs Resistance Patterns of Mycobacterium tuberculosis Isolates from Newly Diagnosed Cases of Tuberculosis. Open Journal of Medical Microbiology, 7, 67-75.

https://doi.org/10.4236/ojmm.2017.73006

Received: August 29, 2017

Accepted: September 26, 2017

Published: September 29, 2017

Copyright $\odot 2017$ by authors and Scientific Research Publishing Inc. This work is licensed under the Creative Commons Attribution International License (CC BY 4.0).

http://creativecommons.org/licenses/by/4.0/

(c) (i) Open Access

\begin{abstract}
Introduction: Tuberculosis is a major cause of mortality and morbidity worldwide. Anti-tuberculosis drugs have been used for many decades but resistance to them is now widespread. Globally $5 \%$ of tuberculosis cases and in India 3\% among new TB cases. This study was planned to know the pattern of first line anti-tuberculosis drug resistance in south Gujarat, Surat region in newly diagnosed patients of tuberculosis. Material and Methods: 350 samples were processed for homogenisation and concentration using 4\% NAOH-2.9\% trisodium citrate. Processed samples were inoculated in liquid medium that is MGIT (Mycobacterial growth indicator tube). Positive samples for $M$. tbwere processed further for first line anti-tuberculosis drugs sensitivity testing (DST). Reading was taken by using MicroMGIT system. Result: Out of 350 samples 59 (17\%) were positive samples, of which 48 (13\%) were $M . t b$ and 11 (3\%) were non tuberculous mycobacteria. Out of 48 samples $2 \%$ ( 1 isolate) was resistant to isoniazid and Rifampicin while $2 \%$ were monoresistant to isoniazide, $2 \%$ monoresistant to streptomycin. No rifampicin monoresistant was detected. Conclusion: Such study may help in control of tuberculosis at regional and national level which would in turn help in planning of measures to control Multidrug resistance tuberculosis. Continuous surveillance should be applied to know the periodic changing patterns and trend in Drug resistant tuberculosis.
\end{abstract}

\section{Keywords}

M. tuberculosis, First Line Anti-Tuberculosis Drugs, MDR-TB, Prevalence

\section{Introduction}

Tuberculosis is one of the Major causes of mortality and morbidity. In India, in- 
cidence of tuberculosis is 2.2 million (167/lakh/year), prevalence of 2.5 million (195/lakh/year) and Mortality is 2.2 lakhs (17/lakh/year) as per Global TB report, 2015 [1].

Anti-tuberculosis drugs have been used for many decades and resistance to them is now widespread. M. tuberculosis may be resistance to one or more drugs. Anti-tuberculosis drug resistance is a major public health problem which arises due to improper and irrational use of anti-tuberculosis drugs in chemotherapy of drug-susceptible tuberculosis patients. This improper use is a result of a number of actions including administration of improper treatment regimens, and failure to ensure that patients complete the whole course of treatment. A patient who develops active disease with a drug resistant tuberculosis strain can transmit this form of tuberculosis to other individuals.

Multidrug resistant tuberculosis is a form of tuberculosis that has resistant to two most effective first line anti-tuberculosis drugs which are Isoniazid and Rifampicin. Globally, $5 \%$ of tuberculosis cases were estimated to have multi-drug resistance (MDR-TB). In India, 3\% among new TB cases and 12\% - 17\% among previously treated TB cases have MDR-TB [2]. In a study by Surandra K. sharma et al. between 2008 and 2009 in 177 cases of sputum positive pulmonary tuberculosis, MDR-TB rate among newly diagnosed pulmonary tuberculosis was 1.1 percent [3].

As the rate of MDR-TB is variable in different parts of countries, this study was planned to know the pattern of first line anti-tuberculosis resistance in south Gujarat, Surat region in newly diagnosed patients of tuberculosis as no study was planned for the same before.

\section{Material and Methods}

Study was started after ethical approval for the same. 350 newly registered and suspected patients for pulmonary and extra pulmonary tuberculosis in outpatients and inpatients department of new civil Hospital of south Gujarat, Surat were included in the study during the period of October 2013-December 2015. Sample size was calculated based on prevalence rate of new cases of tuberculosis in south Gujarat region. Patients with major diseases like HIV/malignancy/immunocompromised patients/patients on immunosuppressive treatment/patients with past or present history of anti-tuberculosis treatment were excluded.

Samples were processed in biosafety cabinet along with all personal protective measures. As Figure 1. From all samples, direct smear was prepared first for $\mathrm{Z} \mathrm{N}$ and fluorescence stain and they were processed for decontamination and concentration by $4 \% \mathrm{NAOH}-2.9 \%$ tri Sodium citrate to increase the yield of isolation of $M . t b$ and to prevent contamination. Then $0.5 \mathrm{ml}$ of processed samples were inoculated into liquid medium that is $7 \mathrm{ml}$ MGIT (Mycobacterial growth indicator tubes) tubes along with $0.8 \mathrm{ml}$ of OADC and PANTA suspension to prevent contamination and to enhance growth of $M . t b$. MGIT tubes were incubated at $37^{\circ} \mathrm{C}$ in incubator. Reading for liquid medium were taken by microM 


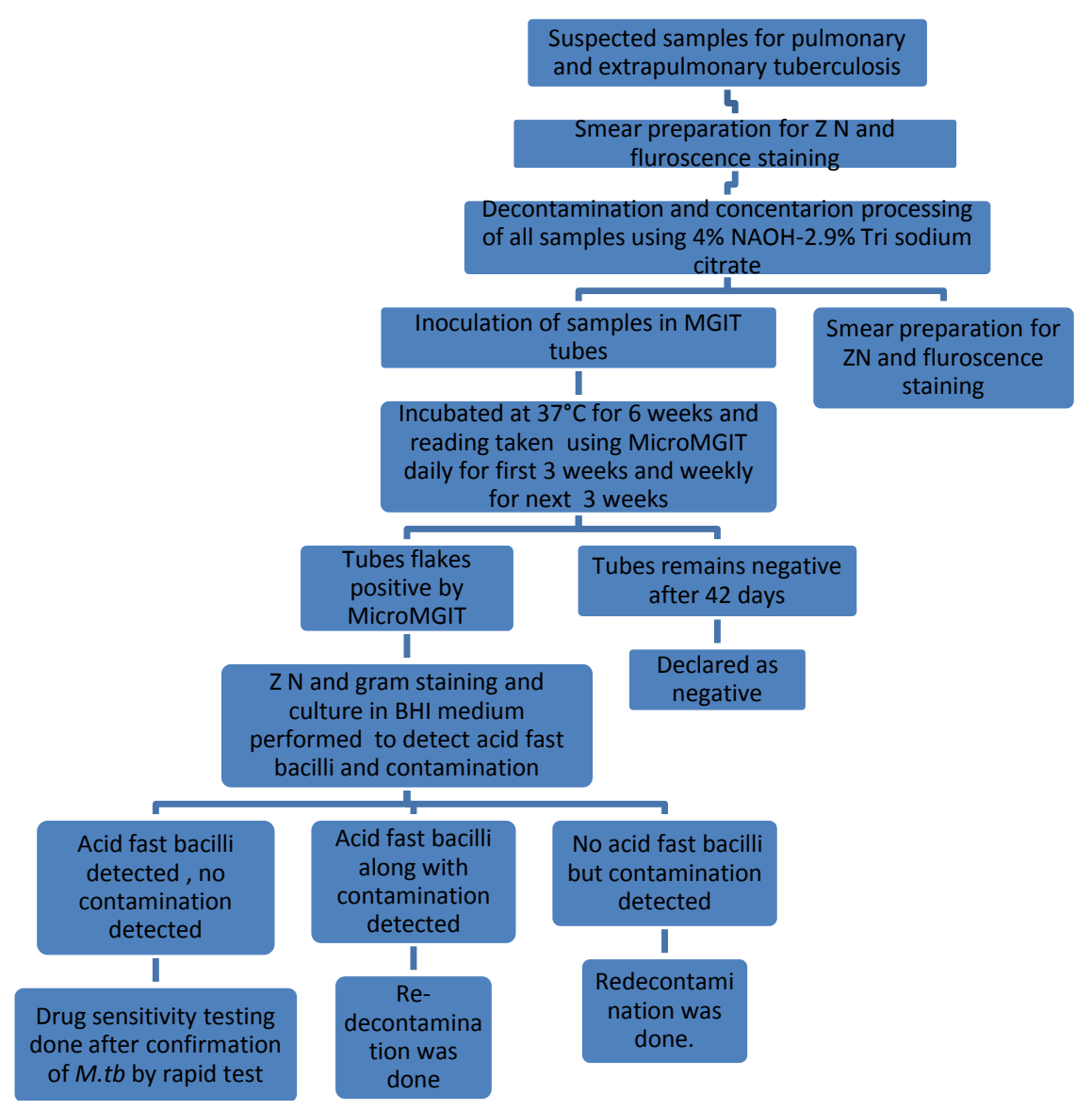

Figure 1. Protocol for processing of samples.

GIT system daily in first 3 weeks and then once a week for next 3 weeks. Positive tubes were confirmed for $M$. $t b$ by Z N smear and rapid kit (SD BIOLINE TB Ag MPT64) for detection of $M$. $t b$ complex. Drug sensitivity testing was done in liquid culture-MGIT by $1 \%$ proportion method with as per protocol described by MGIT Manual-FIND Diagnostics with critical concentration of drugs of $1.0 \mathrm{~g} / \mathrm{ml}$ for Streptomycin, $0.1 \mu \mathrm{g} / \mathrm{ml}$ for Isoniazid, $1.0 \mu \mathrm{g} / \mathrm{ml}$ of Rifampicin and $5.0 \mu \mathrm{g} / \mathrm{ml}$ of Ethambutol [4].

\section{Result}

Sample wise, Area wise and age group wise distribution of 350 samples is described in Figures 2-4 respectively which shows that maximum suspected cases (62\%) were pulmonary tuberculosis with sputum as a representative sample, maximum suspected cases were found in tuberculosis ward. Maximum suspected cases (59\%) were found in age group of 21 - 40 year. Male to female ratio of 350 suspected cases is $2.7: 1$.

Out of 350 samples, 48 samples were $M . t b$ and 11 were non tuberculosis mycobacteria (NTM). In positive samples male were 34 and female were 14 with male to female ratio in positive samples was 2.4:1 Age group wise distribution of positive samples shows that maximum samples were from age group of $21-40$ 


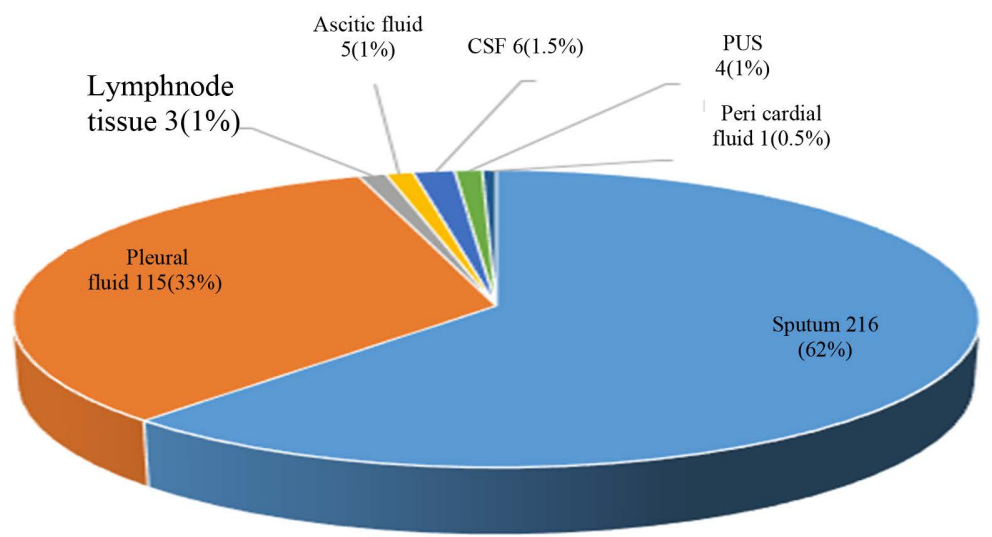

Figure 2. Sample wise distribution of all suspected samples.



Figure 3. Area wise distribution of suspected patients.

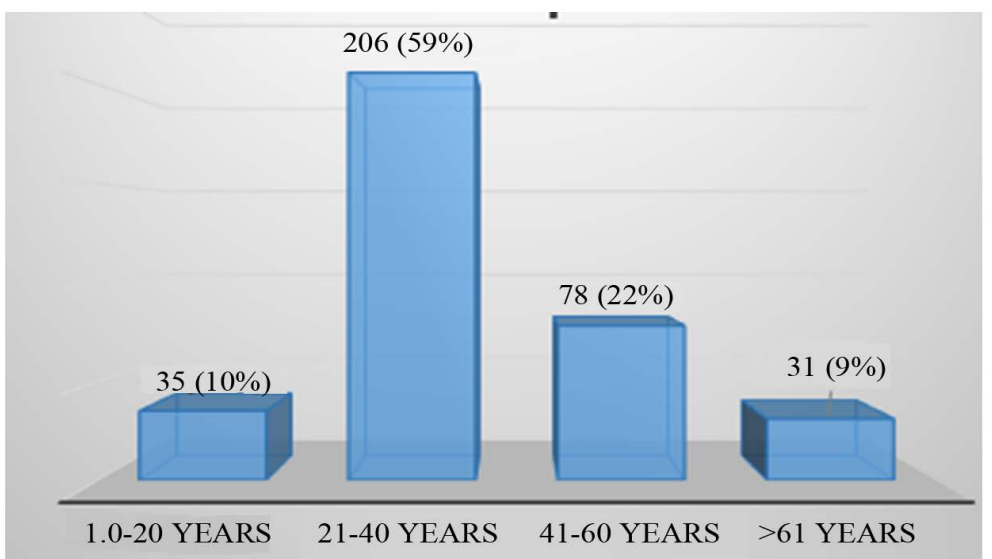

Figure 4. Age group wise distribution of suspected patients.

year which is shown in Figure 5 and was statistically significant by ANOVA test with $\mathrm{p}$ value less than 0.01 . 
Area wise and sample wise distribution of 48 positive samples is described in Figure 6 and Figure 7 respectively which shows that maximum positive samples (65\%) were from outpatient department and maximum positive samples were Sputum (83\%). ZN and Fluorescence microscopy results of 48 samples before and after processing of positive samples is shown in Figure 8 and Figure 9.

When both staining methods were compared, there is a statistically significant difference of rate of positivity by fluorescence method when tested by fisher extract/Mid P-extract test with $\mathrm{p}$ value less than 0.05 . Also there is a statistically significant difference to obtain positive result after digestion and decontamination method.

Drug resistant pattern of 48 positive samples is shown in Table 1 and Table 2.

\section{Discussion}

Despite the remarkable efforts to control $\mathrm{TB}$, the disease remains one of the most serious infectious diseases. Moreover, important issues regarding drug resistant have emerged. The reported prevalence of drug resistant TB was found

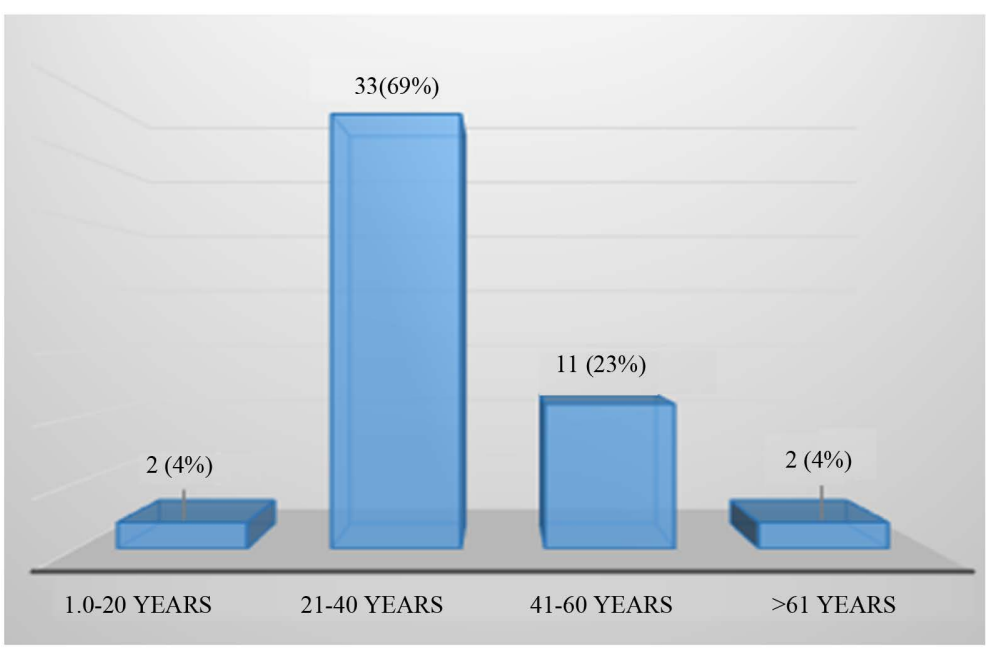

Figure 5. Age group wise distribution of positive samples.

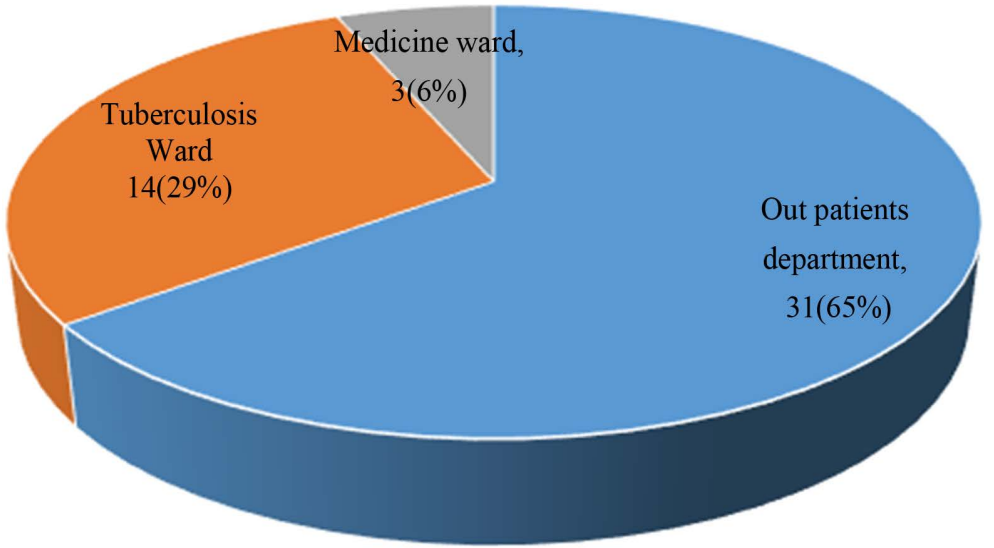

Figure 6. Area wise distribution of positive samples. 




Figure 7. Sample wise distribution of positive sample.

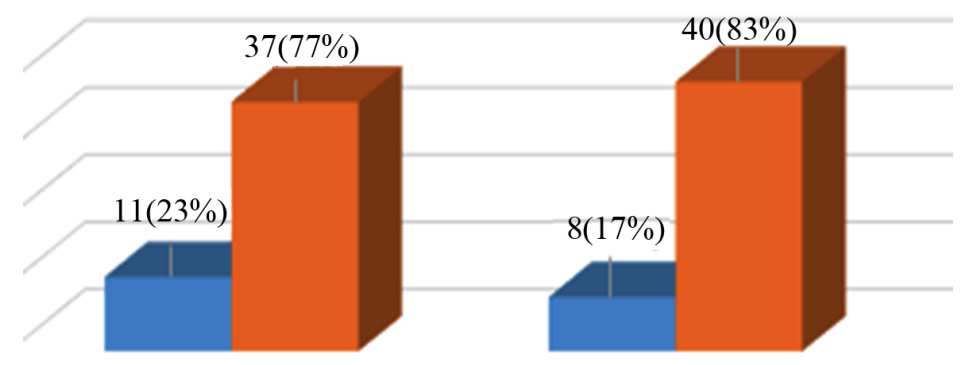

By ZN stain

By Fluorescence stain

Negative Positive

Figure 8. Comparison of $\mathrm{Z} \mathrm{N}$ and fluorescence stain results of 48 positive samples before processing of samples.

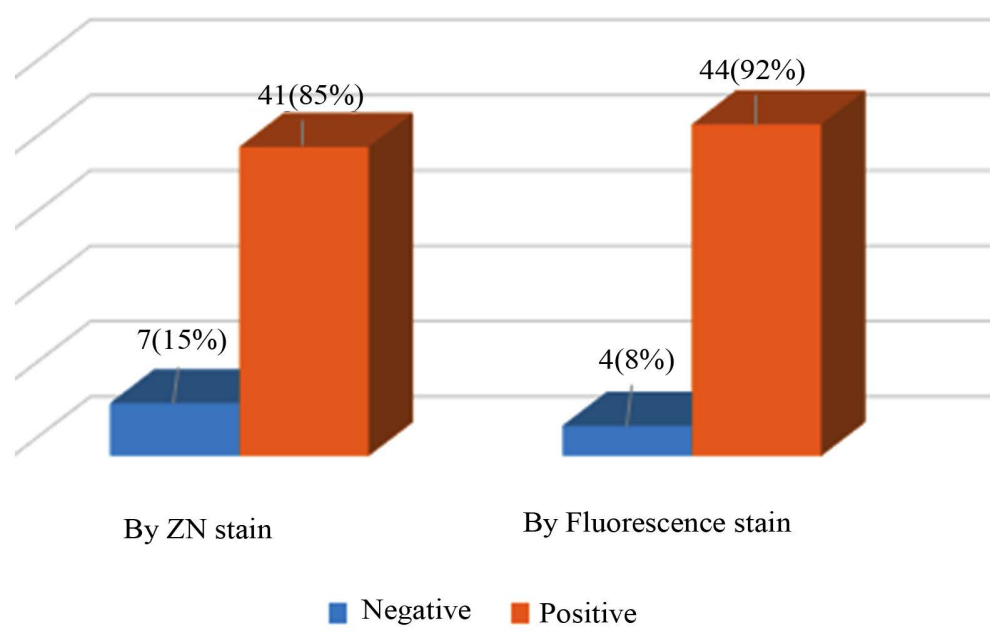

Figure 9. Comparison of $\mathrm{Z} \mathrm{N}$ and fluorescence stain results of 48 positive samples after processing of samples.

variable in different studies from around the world.

Gender wise distribution of all suspected samples shows male to female ratio 
Table 1. Number of isolates showing resistant to first line anti-tuberculosis drugs.

\begin{tabular}{cc}
\hline Resistance pattern & $\begin{array}{c}\text { Number of isolates showing resistant } \\
\text { (out of } 48 \text { samples) }\end{array}$ \\
\hline Isoniazide + Rifampicin & 1 \\
Isoniazide alone & 1 \\
Rifampicin alone & 0 \\
Streptomycin alone & 1 \\
Isoniazide + streptomycin & 1 \\
\hline
\end{tabular}

Table 2. Different type of resistant pattern to first line drugs by manual MGIT system.

\begin{tabular}{cccc}
\hline Type of drug resistant & Mono-drug resistance & Poly-drug resistance & Multi-drug resistance \\
\hline No. of isolates & 2 & 1 & 1 \\
& $\begin{array}{c}1 \text { isolate resistant to } \\
\text { Isoniazid and 1 isolate } \\
\text { resistant to streptomycin }\end{array}$ & $\begin{array}{c}\text { resistant to Isoniazid and } \\
\text { streptomycin }\end{array}$ & $\begin{array}{c}\text { resistant to Isoniazid } \\
\text { and Rifampicin }\end{array}$ \\
\hline
\end{tabular}

of 2.7:1, which suggest that male is registered more than female for diagnosis of tuberculosis. A study done by Sukesh rao, in Mangalore, Karnataka, India has reported male to female ratio of 2:1 [5]. This issue could be attributed to behavioral factors for tuberculosis such as smoking, alcohol consumption and malnutrition higher in males than females and the delay in seeking medical treatment in men. Majority of suspected patients were in the age group of $21-40$ year which correlates with contact to outside population in this age group more than other age group.

There is statistically significance difference in rate of positivity of smear by ZN and fluorescence stain (based on Fisher extract with $P$ value less than 0.05), which suggest that fluorescence microscopy is better than light microscopy by $\mathrm{Z}$ $\mathrm{N}$ stain. Recently use of LED microscope also decreases the cost in purchase of fluorescence microscope in lower income countries like India.

Drug sensitivity testing of first line anti-tuberculosis drug was performed using liquid culture MGIT, results of which were available between 8 - 10 days after keeping drug sensitivity. Use of Liquid culture over Solid LJ medium decreases the duration in isolation of $M . t b$ from sample and to perform DST, which helps in early diagnosis and treatment of MDR-TB patients.

Out of 48 samples 4 strains had shown resistance, of which one strain had shown resistant to Isoniazid and Rifampicin, one strain had shown resistant to Isoniazid and Streptomycin, one with resistant to Streptomycin alone and Isoniazid alone. In our study monoresistance in Isoniazid, Ethambutol and Streptomycin was $2.08 \%$ and no Rifampicin mono resistance was detected. Initial resistance to rifampicin ranged from $0 \%-3 \%$ and the rate of ethambutol resistance was $0 \%-4.2 \%$ globally [6] [7]. In India the initial drug resistance to INH is $18 \%-20 \%, 4.8 \%-14 \%$ for streptomycin. In the early 1990s, a retrospective study done at New Delhi showed a high level of primary drug resistance to iso- 
niazid (18.5\%) and a low level of rifampicin resistance [8]. Data from India on acquired resistance to the ant tuberculosis drugs showed that any resistance to INH was in between $47.7 \%-87.1 \%$, for rifampicin it was $28.3 \%-80.6 \%$.

Specific measures are being taken within the Revised National Tuberculosis Control Programme to address the MDR_TB problems through appropriate management of patients and strategies to prevent the propagation and dissemination of MDR-Tb. Drug resistant TB has microbial, clinical, and programmatic causes.

This study will help us to screen the prevalence of MDR-TB among the patients of south Gujarat. Throughout the course of this study, we felt the need for further study involving bigger number of samples, looking into prevalence of non-tubercular mycobacteria (NTM) and its differentiation and testing resistance pattern for second line drugs

\section{Conclusion}

Tuberculosis has been a significant health hazard in India, but the change in its nature with higher prevalence of MDR-Tb has made it more important to do more research in this field to produce regional data. Such study may help in control of tuberculosis at regional and national level which would in turn help in planning of measures to control of such MDR-Tb. In addition, continuous surveillance should be applied to know the periodic changing patterns and trend in Drug resistant tuberculosis.

\section{Limitations}

In our study, more detail analysis about patient's clinical history, X-ray finding, Laboraory investigation (ESR, CBC, Monteux test)), locality wise survey of TB cases were not possible.

\section{References}

[1] RNTCP (2010) New Delhi: Central TB Division. Directorate General of Health Services, Ministry of Health and Family Welfare. Status TB Report, RNTCP, New Delhi.

[2] World Health Organization (2015) Global Tuberculosis Report 2014. World Health Organization, Genava.

[3] Sharma, S.K., Kaushik, G., Jha, B., George, N., Arora, S.K., Gupta, D., Singh, U., Hanif, M. and Vashisht, R.P. (2011) Prevalence of Multidrug Resistant among Newly Diagnosed Cases of Sputum-Positive Pulmonary Tuberculosis. Indian Journal of Medical Research, 133, 308-311.

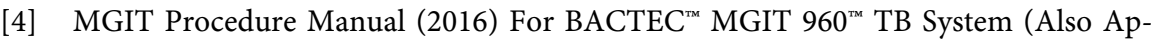
plicable for Manual MGIT).

[5] Rao, S. (2009) Tuberculosis and Gender: An Analysis and Its Implication in Tuberculosis Control. Lung India, 26, No. 2.

[6] World Health Organization. (2003) WHO Report 2003: Global Tuberculosis Control-Surveillance, Planning, Financing. WHO, Geneva. 
[7] Cohn, D.L., Bustreo, F. and Raviglione, M.C. (1997) Drug Resistant Tuberculosis; Review of the World Wide Situation and the WHO/IUATLD Gobal Surveillance Project. International Union against Tuberculosis and Lung Disease. Clinical Infectious Diseases, 24, S121-130. https://doi.org/10.1093/clinids/24.Supplement 1.S121

[8] Paramasivan, C.N., Venkataraman, P., Chandrasekaran, V., Bhat, S. and Narayan, P.R. (2002) Surveillance of Drug Resistance in Tuberculosis in Two District of South India. International Journal of Tuberculosis and Lung Disease, 6, 479-484.

Submit or recommend next manuscript to SCIRP and we will provide best service for you:

Accepting pre-submission inquiries through Email, Facebook, LinkedIn, Twitter, etc. A wide selection of journals (inclusive of 9 subjects, more than 200 journals) Providing 24-hour high-quality service User-friendly online submission system Fair and swift peer-review system Efficient typesetting and proofreading procedure Display of the result of downloads and visits, as well as the number of cited articles Maximum dissemination of your research work

Submit your manuscript at: http://papersubmission.scirp.org/ Or contact ojmm@scirp.org 